\title{
3-/3,5-Pyrrole-substituted BODIPY derivatives and their photophysical and electrochemical studies
}

\author{
KARTHIKA J KADASSERY, ${ }^{\mathrm{a}, \#}$, AKANKSHA NIMESH ${ }^{\mathrm{a}, \mathrm{b}}$, SANOJ RAJ $^{\mathrm{a}, \$}$ and \\ NEERAJ AGARWAL ${ }^{\mathrm{a}, *}$ \\ ${ }^{a} U M-D A E$, Centre for Excellence in Basic Sciences, Health center building, Kalina campus, Santacruz (E), \\ Mumbai, 400098 India \\ ${ }^{b}$ Department of Chemistry, Indian Institute of Technology Kanpur, Kanpur, 208016 India \\ ${ }^{\#}$ Current address: Department of Chemistry, University at Buffalo, Buffalo, NY 14260, USA \\ ${ }^{\$}$ Current address: Department of Chemistry, University of Illinois at Chicago, Chicago, Illinois 60607, USA \\ e-mail: na@cbs.ac.in
}

MS received 7 February 2016; revised 1 July 2016; accepted 3 July 2016

\begin{abstract}
Nucleophilic substitution on 3-bromo/3,5-dibromo-4,4'-difluoro-8-(aryl)-4-bora-3a,4a-diaza-sindacene (BODIPY), substituted with anisyl or thienyl at meso positions, with neat pyrrole afforded the mono and di-pyrrole substituted BODIPYs 1-4 in good yields. Large bathochromic shifts, upto $\sim 180 \mathrm{~nm}$ in absorption maxima (581-682 nm), and fluorescence maxima (606-695 nm) were observed for these BODIPYs. Absorption and fluorescence properties were studied in different solvents to compare the effect of mono and di substitution on BODIPY. The Lippert-Mataga equations were used which predict strong polarization of mono substituted BODIPYs. Electrochemical studies were carried out to find the oxidation potential and HOMO energy levels were calculated. Theoretical studies of 1-4 provide the insight on the electron density distribution in 1-4. Theoretical and experimental photo-physical studies in different solvents were correlated to find the substituent effects on BODIPY.
\end{abstract}

Keywords. BODIPY; charge transfer; lippert-mataga equation; solvatochromism.

\section{Introduction}

4,4'-Difluoro-4-bora-3a,4a-diaza-s-indacene (BODIPY) is a popular dye family having high molar absorption coefficient, sharp absorption and fluorescence spectra and has been studied by many research groups. ${ }^{1-3}$ Tunable photophysical and electrochemical properties of BODIPY dyes make them attractive for chemosensors, photovoltaic applications, fluorescence probes and biological applications. ${ }^{4-11}$ BODIPYs are widely used as labeling dyes or as fluorescence sensors in biological systems owing to their excellent photophysical properties and stability in physiological conditions. The development of near-infrared (NIR) derivatives of BODIPY have recently gained much attention for their applications in fluorescence imaging and in photodynamic therapy. For example, pyrrole-containing BODIPYs such as BODIPY 576/589 and BODIPY 650/665 have been commercialized and their analogues have been widely used as red fluorescent dyes. Another recent application of BODIPY is their use in the up-conversion of energy by triplet-triplet annihilation due to their low lying triplet energy levels. ${ }^{12}$ For various applications of BODIPYs, photophysical as well as electrochemical properties could be altered by changing the substituents on its core. Various parameters such as distribution of electron density, effective conjugation length, solubility in different types of solvents, conjugates with other chromophores were used to tune the properties of BODIPYs. ${ }^{13-20}$ Coupling reactions have been employed on BODIPY to introduce aryl substituents in the presence of transition metal catalysts and recently without using metal catalyst. ${ }^{21-33}$

The recent developments in direct functionalization rather than the inter-conversion of organic groups have opened up a rapidly expanding field of BODIPY chemistry. ${ }^{34,35}$ Introduction of nucleophiles via nucleophilic aromatic substitution (SNAr) have been reported recently on halogen substituted BODIPY. ${ }^{34,35}$ The same group showed the oxidative nucleophilic substitution at 3-position of non-halogenated BODIPY. ${ }^{36}$ Lijuan Jiao et al., reported the direct oxidative nucleophilic substitution of the 3-hydrogen of BODIPY by pyrrole under reflux condition in oxygen atmosphere. ${ }^{37}$ Only mono substitution of pyrrole could be achieved by this method which was further shown to be useful to synthesize the carboxaldehyde derivative of BODIPY by Vilsmeier-Haack reaction. Recently, Hao et al. 
reported regioselective substitution on BODIPYs with pyrrole under mild conditions without using any catalyst. ${ }^{38}$

In this article, we report synthesis of both mono and dipyrrole substituted BODIPY derivatives. Halogenated 3,5-dibromo BODIPYs were used with neat pyrrole for the synthesis of mono and di-pyrrolyl BODIPY derivatives 1-4 at 80 and $140^{\circ} \mathrm{C}$, respectively. We observed the stepwise dipyrrolyl substitution which is facilitated by halogenated BODIPY and higher temperature. Density functional theory calculations along with photo-physical and electrochemical properties of these BODIPY derivatives were studied to calculate the various photophysical and electrochemical parameters.

\section{Experimental}

\subsection{Chemicals and instrumentation}

All general chemicals and solvents were procured from S D Fine Chemicals, India and Sigma-Aldrich. Column chromatography was performed using silica gel of 100-200 mesh size. The ${ }^{1} \mathrm{H}$ and ${ }^{13} \mathrm{C}-\mathrm{NMR}$ ( $\delta$ in parts per million) spectra were recorded using a Bruker $500 \mathrm{MHz}$ spectrometer. Tetramethylsilane (TMS) was used as an internal reference for recording ${ }^{1} \mathrm{H}-\mathrm{NMR}$ spectra (residual proton; $\delta=7.26 \mathrm{ppm}$ ) in $\mathrm{CDCl}_{3}$. The MS spectra were recorded on Bruker MALDI-TOF. UV-Vis spectra were acquired on Shimadzu 1800. Fluorescence measurements were carried out using Horiba Fluoromax 4. Cyclic voltammetry measurements were carried out using the electrochemical analyzer $(620 \mathrm{D}$, $\mathrm{CH}$ Instruments Co.) at room temperature by utilizing the three-electrode configuration consisting of $\mathrm{Pt}$ disc (working electrode), platinum wire (auxiliary electrode), and standard calomel (reference electrode) electrodes. The experiments were done in dry chloroform with $0.1 \mathrm{M}$ tetrabutylammoniumhexafluoro phosphate as the supporting electrolyte.

\subsection{Synthesis and characterization of BODIPY derivatives (1-4)}

2.2a 3-pyrrolyl-4,4-difluoro-8-(4-methoxyphenyl)-4bora-3a,4a-diaza-s-indacene, 1: In a reaction flask, $7 \mathbf{a}(0.060 \mathrm{~g}, 0.20 \mathrm{mmol})$ and pyrrole $(0.5 \mathrm{~mL}, 7.4 \mathrm{mmol})$ were stirred at $80^{\circ} \mathrm{C}$ for $3 \mathrm{~h}$. Excess pyrrole was evaporated at reduced pressure and crude compound obtained was purified using silica gel chromatography, using 1:1 hexane and dichloromethane, to get the pure compound 1 as purple solid. [Yield: 62\%]. M.p.: $>200^{\circ} \mathrm{C} .{ }^{1} \mathrm{H} \mathrm{NMR}\left(500 \mathrm{MHz}, \mathrm{CDCl}_{3}\right): \delta=10.57$ $(\mathrm{s}, 1 \mathrm{H}, \mathrm{NH}), 7.53(\mathrm{~d}, 2 \mathrm{H}, \mathrm{J}=8.6 \mathrm{~Hz}), 7.71(\mathrm{~s}, 1 \mathrm{H}), 7.22$ $(\mathrm{s}, 1 \mathrm{H}), 7.01-7.06(\mathrm{~m}, 4 \mathrm{H}), 6.95(\mathrm{~d}, 1 \mathrm{H}, \mathrm{J}=4.6 \mathrm{~Hz})$, $6.73(\mathrm{~d}, 1 \mathrm{H}, \mathrm{J}=3.6 \mathrm{~Hz}), 6.50(\mathrm{~m}, 1 \mathrm{H}), 6.42(\mathrm{~m}, 1 \mathrm{H})$, 3.93 (s, $\left.3 \mathrm{H}, \mathrm{OCH}_{3}\right) \mathrm{ppm}$. MALDI-TOF mass calcd. for $\mathrm{C}_{20} \mathrm{H}_{16} \mathrm{BF}_{2} \mathrm{~N}_{3} \mathrm{O}$ : 363.1 ; found: $363.5(\mathrm{M})^{+}$.

2.2b 3-pyrrolyl-4,4-difluoro-8-(2-thienyl)-4-bora-3a, 4a-diaza-s-indacene, 2: In a reaction flask, $7 \mathbf{b}(0.055 \mathrm{~g}$, $0.20 \mathrm{mmol})$ and pyrrole $(0.5 \mathrm{~mL}, 7.4 \mathrm{mmol})$ were stirred at $80^{\circ} \mathrm{C}$ for $4 \mathrm{~h}$. Excess pyrrole was evaporated under reduced pressure and crude compound obtained was purified using silica gel chromatography, 1:1 hexane and dichloromethane, to obtain the pure 2 as purple solid. [Yield: $57 \%$ ]. ${ }^{1} \mathrm{H}$ NMR $(500 \mathrm{MHz}$, $\left.\mathrm{CDCl}_{3}\right): \delta=10.59(\mathrm{~s}, 1 \mathrm{H}, \mathrm{NH}), 7.70(\mathrm{~s}, 1 \mathrm{H}), 7.63(\mathrm{~d}$, $1 \mathrm{H}, \mathrm{J}=5.1 \mathrm{~Hz}), 7.48(\mathrm{~s}, 1 \mathrm{H}), 7.32(\mathrm{~d}, 1 \mathrm{H}, \mathrm{J}=4.5 \mathrm{~Hz})$, $7.25(\mathrm{~s}, 2 \mathrm{H}), 7.08(\mathrm{~s}, 1 \mathrm{H}), 7.01(\mathrm{~s}, 1 \mathrm{H}), 6.98(\mathrm{~d}, 1 \mathrm{H}$, $\mathrm{J}=4.5 \mathrm{~Hz}), 6.51(\mathrm{~s}, 1 \mathrm{H}), 6.43(\mathrm{~s}, 1 \mathrm{H}) \mathrm{ppm} .{ }^{13} \mathrm{C} \mathrm{NMR}$ $\left(500 \mathrm{MHz}, \mathrm{CDCl}_{3}\right): \delta=151.5,137.5,136.5,135.1$, 133.0, 131.3, 129.3, 127.6, 126.6, 125.0, 123.6, 121.2, 118.7, 115.9, $111.7 \mathrm{ppm}$. MALDI-TOF mass calcd. for $\mathrm{C}_{17} \mathrm{H}_{12} \mathrm{BF}_{2} \mathrm{~N}_{3} \mathrm{~S}$ : 339.17 ; found: $338.47(\mathrm{M})^{+}, 318.65$ $(\mathrm{M}-\mathrm{F})^{+}$.

2.2c 3-bis-(pyrrolyl)-4,4-difluoro-8-(4-methoxyphenyl)4-bora-3a,4a-diaza-s-indacene, 3: In a reaction flask, 7b $(0.06 \mathrm{~g}, 0.20 \mathrm{mmol})$ and pyrrole $(1.2 \mathrm{~mL}, 18 \mathrm{mmol})$ were stirred at $140^{\circ} \mathrm{C}$ for $22 \mathrm{~h}$. Excess pyrrole was evaporated at reduced pressure and crude compound obtained was purified using silica gel chromatography, using 1:2 hexane and dichloromethane, to obtain compound 3 as greenish purple solid. [Yield: $22 \%$ ]. ${ }^{1} \mathrm{H}$ NMR $\left(500 \mathrm{MHz}, \mathrm{CDCl}_{3}\right): \delta=10.28($ br s, $1 \mathrm{H}, \mathrm{NH})$, $7.71(\mathrm{~d}, 2 \mathrm{H}, \mathrm{J}=8.6 \mathrm{~Hz}), 7.15(\mathrm{~s}, 2 \mathrm{H}), 7.06(\mathrm{~d}, 2 \mathrm{H}, \mathrm{J}=$ $8.6 \mathrm{~Hz}), 6.91$ (s, 2H), 6.81-6.83 (m, 4H), 6.40 (s, 2H), $3.63\left(\mathrm{~s}, 3 \mathrm{H}, \mathrm{OCH}_{3}\right) \mathrm{ppm}$. MALDI-TOF mass calcd. for $\mathrm{C}_{24} \mathrm{H}_{19} \mathrm{BF}_{2} \mathrm{~N}_{4} \mathrm{O}$ : 428.2 ; found: $428.6(\mathrm{M})^{+}$.

2.2d 3-bis-(pyrrolyl)-4,4-difluoro-8-(2-thienyl)-4-bora3a,4a-diaza-s-indacene, 4: A mixture of $\mathbf{8 b}(54 \mathrm{mg}$, $0.20 \mathrm{mmol})$ and pyrrole $(1.2 \mathrm{~mL}, 18 \mathrm{mmol})$ were stirred at $140^{\circ} \mathrm{C}$ for $23 \mathrm{~h}$. Excess pyrrole was evaporated at reduced pressure and crude compound obtained was purified using silica gel chromatography, using 1:2 hexane and dichloromethane, to get the greenishpurple solid of compound 4. [Yield: $17 \%$ ]. ${ }^{1} \mathrm{H}$ NMR $\left(500 \mathrm{MHz}, \mathrm{CDCl}_{3}\right): \delta 10.29$ (s br, 2H, NH), 7.55-7.60 $(\mathrm{m}, 2 \mathrm{H}), 7.43(\mathrm{~d}, 2 \mathrm{H}, \mathrm{J}=2.2 \mathrm{~Hz}), 7.17(\mathrm{~s}, 2 \mathrm{H}), 7.12$ $(\mathrm{d}, 1 \mathrm{H}, \mathrm{J}=4.2 \mathrm{~Hz}), 6.93(\mathrm{~s}, 2 \mathrm{H}), 6.86(\mathrm{~d}, 2 \mathrm{H}, \mathrm{J}=4.2$ $\mathrm{Hz}), 6.41(\mathrm{~s}, 2 \mathrm{H}) \mathrm{ppm}$. MALDI-TOF mass calcd. for $\mathrm{C}_{21} \mathrm{H}_{15} \mathrm{BF}_{2} \mathrm{~N}_{4} \mathrm{~S}$ : 404.2 ; found: $404.6(\mathrm{M})^{+}$. 


\section{Results and Discussion}

\subsection{Synthesis and characterization}

Compounds 1-4 were synthesized as outlined in Scheme 1. Meso-substituted dipyrromethanes 5 (meso anisyl) and $\mathbf{6}$ (meso thienyl) were synthesized. ${ }^{39}$ Purification by column chromatography afforded $\mathbf{5}$ and $\mathbf{6}$ as white solids. These dipyrromethanes $\mathbf{5}$ and $\mathbf{6}$ were used to synthesize the bromo BODIPYs $\mathbf{7 a}-\mathbf{b}$ and $\mathbf{8 a}-\mathbf{b}$ in a sequence of reactions. ${ }^{40}$ Bromination of $\mathbf{5}$ and $\mathbf{6}$ with one or two equivalents of $\mathrm{N}$-bromosuccinimide at low temperature $\left(-78^{\circ} \mathrm{C}\right)$ in THF afforded the mono and dibromo-dipyrromethanes, respectively, which were further reacted with DDQ (2,3-Dichloro-5,6-dicyano1,4-benzoquinone) at room temperature to get the mono and dibromo-dipyrromethenes. The obtained crude products were quickly passed through the silica gel column to remove the excess DDQ and purified product was reacted with $\mathrm{BF}_{3}$-etherate to get the mono/dibromo BODIPY dye (7a-8a and $\mathbf{7 b}-\mathbf{8 b})$.

Compounds $\mathbf{7 a}-\mathbf{b}, \mathbf{8 a}-\mathbf{b}$ were subsequently used for nucleophilic substitution with pyrrole to synthesize BODIPY derivatives 1-4 (Scheme 1). Compounds 7a and $\mathbf{8 a}$ were reacted with pyrrole at $80^{\circ} \mathrm{C}$ to get mono pyrrole substituted products $\mathbf{1}$ and $\mathbf{2} \cdot{ }^{37,38}$ To synthesize the dipyrrole substituted BODIPY, 7b-8b were reacted with pyrrole at $80^{\circ} \mathrm{C}$ with excess of pyrrole. Further, on increasing the reaction temperature in a step of $10^{\circ} \mathrm{C}$, no extra spot other than monosubstituted product was observed till $130^{\circ} \mathrm{C}$. At $140^{\circ} \mathrm{C}$, a new greenish blue colored compound start forming which later were characterized as disubstituted products, $\mathbf{3}$ and $\mathbf{4}$. The progress of all these reactions were monitored by thin layer chromatography, which clearly indicated the formation of new products and further supported by red shift in absorption bands corresponding to compounds 1-4. Mono-substituted reaction completed within $2 \mathrm{~h}$ while disubstitued reaction progressed slowly and after about $22 \mathrm{~h}$ showed almost complete consumption of bromoBODIPY reactant. A very small amount of mono substituted products were also observed in the reactions at higher temperature $\left(140^{\circ} \mathrm{C}\right)$. The crude product was purified by chromatography on silica gel column to afford dark blue-black solids of BODIPYs 1-4. Mono and disubstituted products moved quite close to each other in column chromatography. Absorption spectroscopy was used to monitor the fractions containing mono and di substituted BODIPY. The yields of compounds 1 and 2 were good $(\sim 60 \%)$ while it was poor (20\%) for $\mathbf{3}$ and $\mathbf{4}$.

Compounds 1-4 are fairly soluble $(\sim 10 \mathrm{mg} / \mathrm{mL})$ in common organic solvents such as toluene, chloroform, dichloromethane, acetonitrile and dimethylformamide. The identities of the compounds were confirmed by

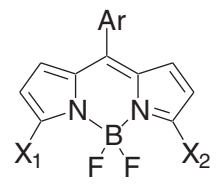

$\mathrm{Ar}=$ Anisyl, $\mathrm{X}_{1}=\mathrm{H}, \mathrm{X}_{2}=\mathrm{Br}, 7 \mathrm{a}$ $\mathrm{Ar}=$ Anisyl, $\mathrm{X}_{1}=\mathrm{X}_{2}=\mathrm{Br}, 7 \mathrm{~b}$ $\mathrm{Ar}=$ Thienyl, $\mathrm{X}_{1}=\mathrm{H}, \mathrm{X}_{2}=\mathrm{Br}, \mathbf{8 a}$ $\mathrm{Ar}=$ Thienyl, $\mathrm{X}_{1}=\mathrm{X}_{2}=\mathrm{Br}, \mathbf{8 b}$

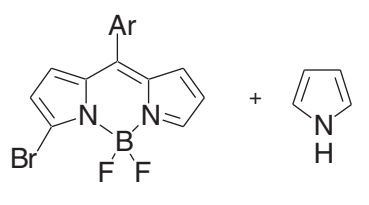

$7 a$ or $8 a$

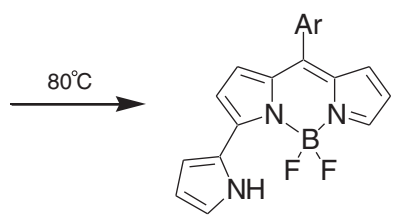

$\mathrm{Ar}=$ Anisyl, 1 $\mathrm{Ar}=$ Thienyl, 2

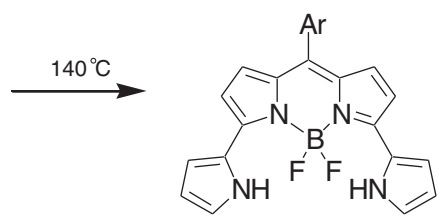

Ar = Anisyl, 3 $\mathrm{Ar}=$ Thienyl, 4

Scheme 1. Synthetic scheme for the BODIPY derivatives 1-4. 


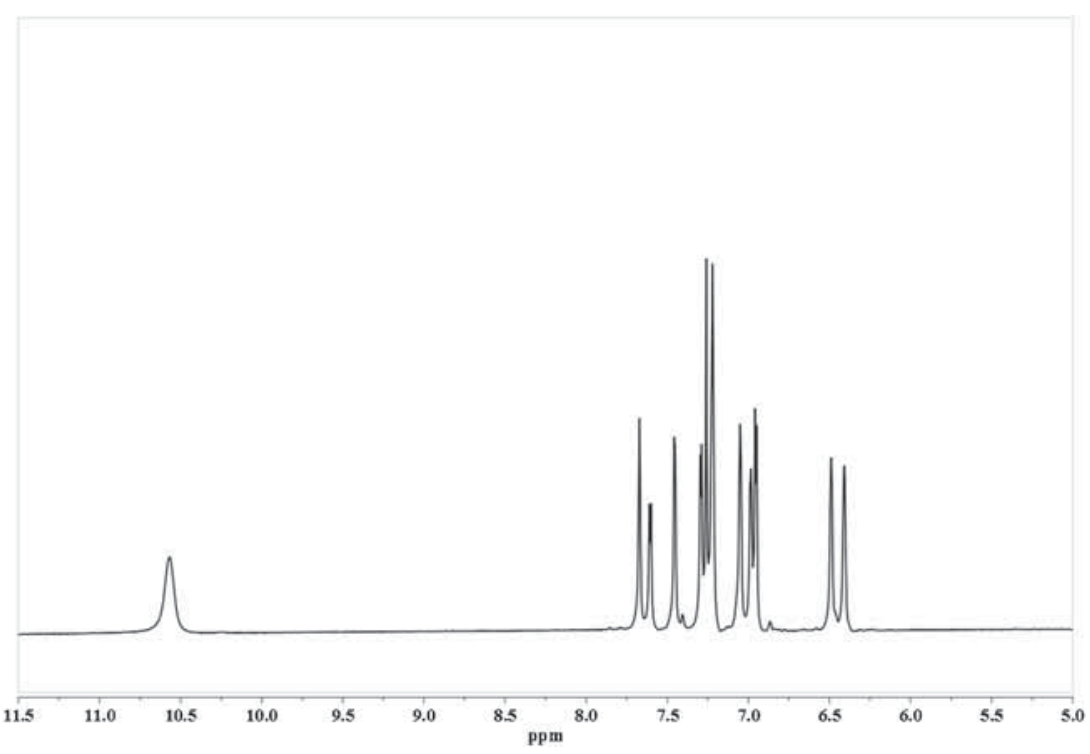

Figure 1. ${ }^{1} \mathrm{H}$ NMR spectrum of compound 2 in $\mathrm{CDCl}_{3}$.

spectroscopic techniques. The ${ }^{1} \mathrm{H}$ NMR spectra of compounds 1-4 showed the characteristic NMR signals corresponding to BODIPY core with additional hetero pyrrolyl proton signals of substituted groups and broad $\mathrm{NH}$ protons. A representative ${ }^{1} \mathrm{H}$ NMR spectrum for compound 2 recorded in $\mathrm{CDCl}_{3}$ is shown in Figure 1. Analysis of ${ }^{1} \mathrm{H}$ NMR revealed the unsymmetrical nature of compound $\mathbf{2}$ as all BODIPY protons appeared as different positions and showed separate signals. Signal for $\mathrm{NH}$ proton was observed at $10.56 \mathrm{ppm}$. Observation of molecular ion peak for 1-4 confirms the formation of these BODIPY derivatives.

\subsection{Photophysical studies}

Photophysical properties of BODIPY has been studied extensively in various non-polar and polar solvents using absorption and fluorescence techniques. ${ }^{41,42}$ To investigate the photophysical properties of $\mathbf{1 - 4}$, we recorded their steady-state absorption and fluorescence excitation and emission spectra in several solvents. Also we recorded the fluorescence decay in toluene using TCSPC technique and determined the position of the absorption and emission maxima, the fluorescence quantum yields $(\phi)$, the rate constants of radiative $\left(k_{\mathrm{r}}\right)$ and non-radiative $\left(k_{\mathrm{nr}}\right)$ deactivation, Stokes shifts, fluorescence lifetimes $(\tau)$, excited state dipole moments and molar absorption coefficients $(\varepsilon)$ of these compounds (1-4). Absorption spectra of $\mathbf{1 - 4}$ in toluene are shown in Figure 2. Compounds 1-4 showed strong absorption maxima in the range of 584-682 $\mathrm{nm}$ and is assigned for $S_{0}-S_{1}\left(\pi-\pi^{*}\right)$. This band is assigned to diisoindolomethene core of compounds $\mathbf{1 - 4}$. The absorption maximum of this band is directly dependent on the extent of de-localization of $\pi$ electrons of pyrrole groups on BODIPY core. The broad band observed in the high energy region $410-470 \mathrm{~nm}$ corresponds to the $\mathrm{S}_{0}-\mathrm{S}_{2}\left(\pi-\pi^{*}\right)$ transition of the boradiazaindacene. Substitution of one pyrrole produced bathochromic shift of around 85-95 nm where as substitution at both 3and 5- position by pyrrole produced large red shift of $\sim 180 \mathrm{~nm}$ in absorption maximum, in comparison to unsubstituted BODIPY. ${ }^{43}$ Various photophysical parameters for $\mathbf{1 - 4}$, determined by absorption and emission spectroscopies, are given in Table 1 .

Emission spectra of compounds 1-4 recorded in toluene are shown in Figure 2. Compounds 1-4 showed emission peak maxima between $\sim 600-700 \mathrm{~nm}$ with a broad tail further in lower energy region (in NIR). A large bathochromic shift of $\sim 180 \mathrm{~nm}$ was observed in comparison to unsubstituted BODIPY. ${ }^{43}$ Absorption and emission bands of the new BODIPY $\mathbf{1}$ and $\mathbf{2}$ are well-separated from each other and showed large Stoke shift compared to unsubstituted BODIPY. The BODIPYs $\mathbf{3}$ and $\mathbf{4}$ which are symmetrical in nature showed very small Stokes shift. The small Stokes shift in BODIPY 3 and 4 suggests small change in geometry of ground and excited states. Fluorescence quantum yields of compounds 1-4 were calculated with respect to Rhodamine B $(\phi=0.68 \text { in ethanol })^{44}$ (Table 1$)$. Fluorescence quantum yields were found to be as high as 0.8 . Single exponential fluorescence decays were observed for 1-4. Fluorescence life time, radiative decay $\left(\mathrm{k}_{\mathrm{r}}\right)$ and non-radiative decay $\left(\mathrm{k}_{\mathrm{nr}}\right)$ constants were calculated and are summarized in Table 1.

Solvatochromism was studied for compounds 1-4 using absorption and emission spectroscopy in several polar and non-polar solvents such as hexane, toluene, 


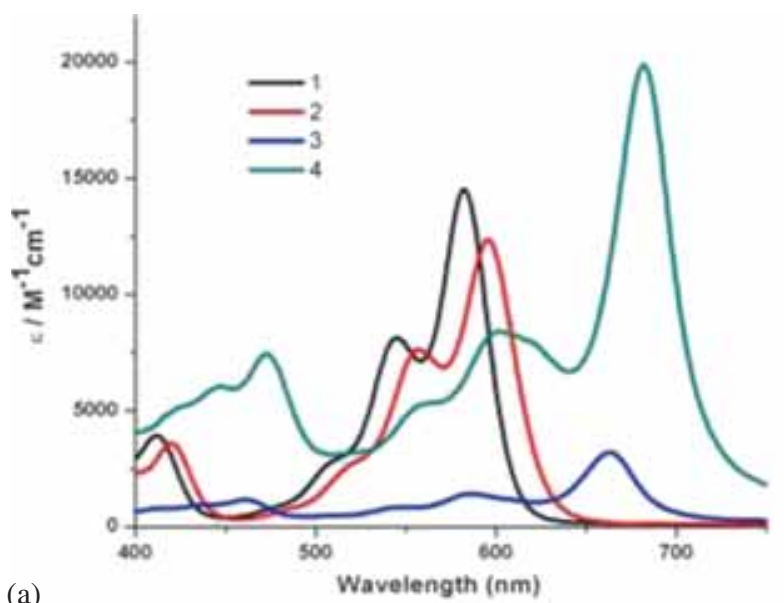

(a)

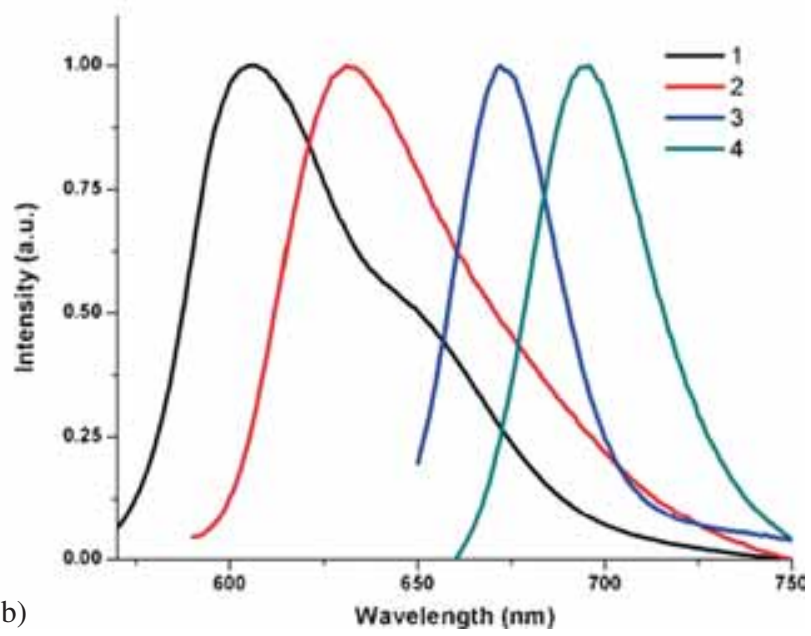

(b)

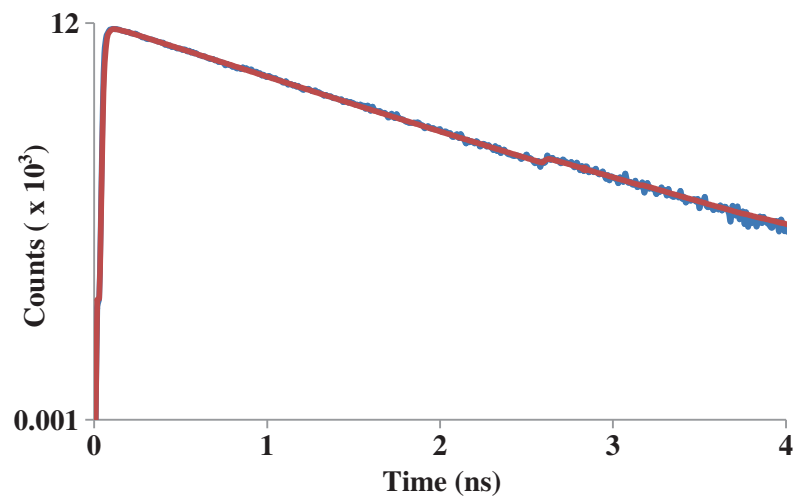

Figure 2. (a) Absorption, (b) normalized emission spectra of compounds 1-4, and (c) fluorescence decay profile of $\mathbf{3}$ in toluene.

DCM, chloroform, ethyl acetate, methanol and DMF (See Supplementary Information). It is evident from these studies that a large Stokes shift was observed for compounds $\mathbf{1}$ and $\mathbf{2}$ as compared $\mathbf{3}$ and $\mathbf{4}$. This trend provides information about considerable change in the dipole moment in excited state of $\mathbf{1}$ and 2. Large Stokes shift is observed when polarity of solvent is increased which suggests the more interaction of excited state in polar solvents and high sensitivity towards polar solvents. The Lippert-Mataga equations ${ }^{45}$ (1 and 2) were used to study the solvent polarity behavior on absorption and emission properties of 1-4. Also they were used to calculate the ratio of dipole moments in ground and excited state as described below.

$$
\begin{aligned}
& \left(v_{a}-v_{f}\right)=\frac{2\left(\mu_{e}-\mu_{g}\right)^{2}}{h c a^{3}}\left(\frac{\varepsilon-1}{2 \varepsilon+1}-\frac{n^{2}-1}{2 n^{2}+1}\right)+K \\
& \left(v_{a}+v_{f}\right)=\frac{2\left(\mu_{e}^{2}-\mu_{g}^{2}\right)}{h c a^{3}}\left(\frac{\varepsilon-1}{2 \varepsilon+1}+\frac{n^{2}-1}{2 n^{2}+1}\right)+K^{\prime}
\end{aligned}
$$

In the above equations, $v_{a}$ and $v_{f}$ are the absorption and emission frequencies (in $\mathrm{cm}^{-1}$ ), $\mu_{e}$ and $\mu_{g}$ are the dipole moments of molecule in excited state and ground state, $\varepsilon$ and $n$ are the dielectric constant and refractive index of the solvent, respectively, $h$ is the Planck's constant, $\mathrm{c}$ is the speed of light and ' $a$ ' is the cavity radius of the molecule. $K$ and $K^{\prime}$ are constants. Figure 3 shows the plot of $\left(v_{a}-v_{f}\right)$ versus the polarity parameter $F 1 \equiv\left\{(\varepsilon-1) /(2 \varepsilon+1)-\left(n^{2}-1\right) /\left(2 n^{2}+1\right)\right\}$, and plot of $\left(v_{a}+v_{f}\right)$ versus the polarity parameter $F 2 \equiv\left\{(\varepsilon-1) /(2 \varepsilon+1)+\left(n^{2}-1\right) /\left(2 n^{2}+1\right)\right\}$ for $\mathbf{1}-\mathbf{4}$. A better linear fit was observed if one excludes the data point corresponding to methanol from the LippertMataga plot as assessed by the correlation coefficient. Ratio of dipole moments $\left(\mu_{e} / \mu_{g}\right)$, calculated using the slopes were found to be $3.14,4.79,4.41$ and 4.23 for 1-4. It will be worth to note the linear relationship correlation coefficient $r=0.71$ for $\mathbf{1}, r=0.64$ for $\mathbf{2}$, $r=0.88$ for $\mathbf{3}$, and $r=0.83$ for $\mathbf{4}$ in Figure 3(a). The use of Lippert-Mataga equations is limited to transitions where the excited state is emissive state and the excited state dipole moment is independent of solvent polarity. The Lippert-Mataga expression of the Stokes shift depends heavily on the solute's dipole moment upon excitation $\left(\Delta \mu_{g e}=\mu_{e}-\mu_{g}\right)$ and the size of the cavity radius $(a)$. The assumptions made in the derivation of the Lippert-Mataga equation is that only dipole-dipole interactions (point dipoles) are taken into account and the solute polarizability is neglected. The uncertainty over the size of the cavity radius and strong polarization in polar solvents for $\mathbf{1 - 4}$ explains why the determined $\Delta \mu_{\mathrm{ge}}$ is unreliable for $\mathbf{1 - 4}$. Photophysical studies in different solvents suggest the possible charge transfer character in these compounds, more efficiently in mono-pyrrole substituted BODIPYs 1 and 2.

\subsection{Cyclic voltammetry}

Compounds 1-4 were investigated in $\mathrm{CHCl}_{3}$ at a scan rate of $100 \mathrm{mV} / \mathrm{s}$ using tetrabutylammoniumhexafluorophosphate (TBAHFP) as supporting electrolyte. 
Table 1. Photophysical properties of compounds 1-4 in toluene.

\begin{tabular}{lcccccccrr}
\hline Comp & $\begin{array}{c}\lambda_{\mathrm{abs}} \\
\mathrm{nm}\end{array}$ & $\begin{array}{c}\lambda_{\mathrm{em}} \\
\mathrm{nm}\end{array}$ & $\Phi$ & $\begin{array}{c}\tau \\
\mathrm{ns}\end{array}$ & $\begin{array}{c}\mathrm{k}_{\mathrm{r}} \\
10^{9} \mathrm{~s}^{-1}\end{array}$ & $\begin{array}{c}\mathrm{k}_{\mathrm{nr}} \\
10^{9} \mathrm{~s}^{-1}\end{array}$ & $\begin{array}{c}\text { Stoke shift } \\
\mathrm{nm}\end{array}$ & $\begin{array}{c}\mu_{\mathrm{e}} \\
\mu_{\mathrm{e}} / \mu_{\mathrm{g}}\end{array}$ & $\begin{array}{c}\mathrm{a} \mu_{\mathrm{g}} \\
\text { Debye } \\
\text { Debye }\end{array}$ \\
\hline Std & 501 & 516 & - & - & - & - & 15 & 1.17 & - \\
1 & $412,544,581$ & 606 & 0.84 & 2.87 & 0.29 & 0.05 & 25 & 3.14 & 16.80 \\
2 & $421,557,596$ & 633 & 0.1 & 0.32 & 0.31 & 2.81 & 37 & 4.79 & 18.94 \\
3 & $461,585,663$ & 674 & 0.24 & 2.68 & 0.09 & 0.28 & 11 & 4.41 & 20.01 \\
4 & $472,603,682$ & 695 & 0.14 & 3.49 & 0.04 & 0.24 & 13 & 4.95 \\
\hline
\end{tabular}

Std-4,4'-difluoro-8-anisyl-4-bora-3a,4a-diaza-s-indacene, ${ }^{\text {a}}$ Determined using DFT calculations.
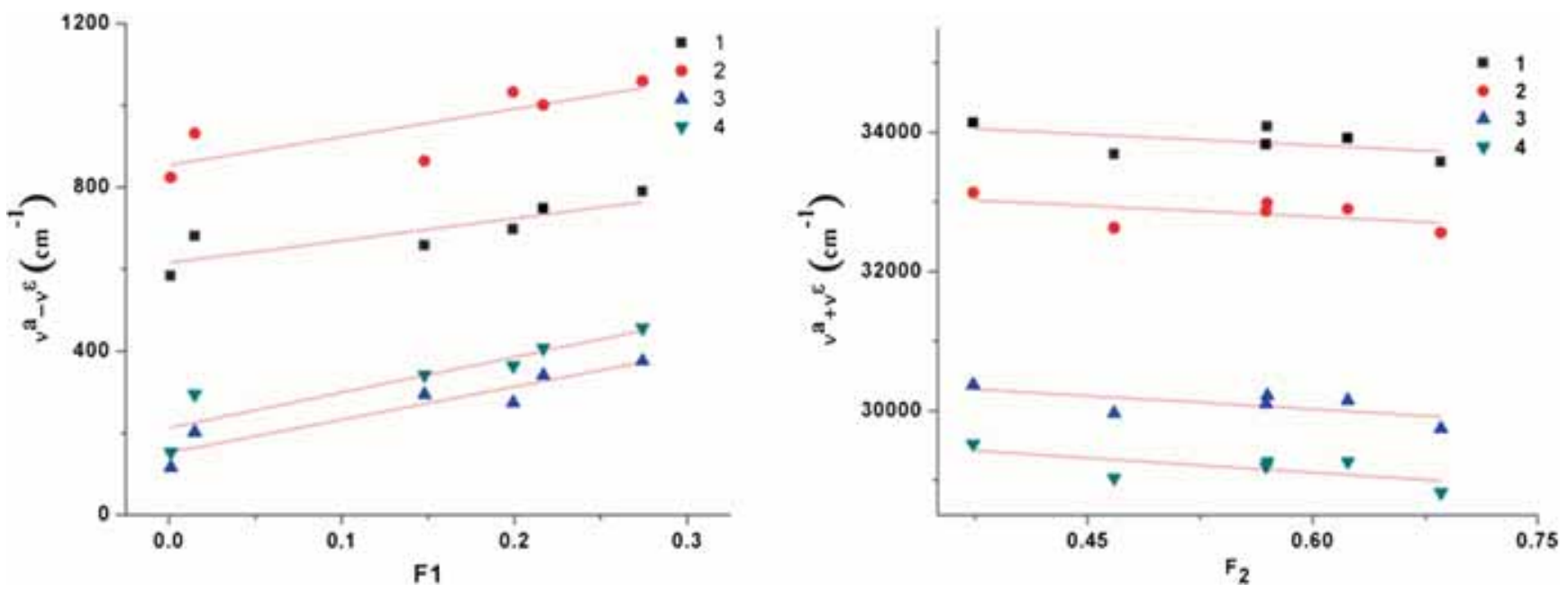

Figure 3. (Right) $\left(v_{a}+v_{f}\right)$ versus the polarity parameter $F 2=\left\{(\varepsilon-1) /(2 \varepsilon+1)+\left(n^{2}-1\right) /\left(2 n^{2}+1\right)\right\}$ for compounds 1-4. (Left) $\left(v_{a}-v_{f}\right)$ versus the polarity parameter $F 1=\left\{(\varepsilon-1) /(2 \varepsilon+1)-\left(n^{2}-1\right) /\left(2 n^{2}+1\right)\right\}$ for compounds $\mathbf{1}-\mathbf{4}$.

Compounds 1-4 showed oxidation waves and they could not be reduced in these experimental conditions. A comparison of oxidation wave of compounds mono and di pyrrole substituted thienyl BODIPY 2, 4 is shown in Figure 4 and oxidation potentials for compounds 1-4 are presented in Table 2. Monopyrrole substituted compounds $\mathbf{1}$ and $\mathbf{2}$ showed irreversible oxidation peaks at $\sim 0.97 \mathrm{~V}$ while disubstituted compounds 3 and 4 showed it at $\sim 0.62 \mathrm{~V}$. This suggests that substitution of BODIPY by two pyrroles make them electron rich and hence make them easy to oxidize. Irreversible oxidation peak suggest the instability of oxidized BODIPYs. Low oxidation potentials make compounds 1-4 suitable for electron donating agents in electronic/photovoltaic devices and biological applications. ${ }^{46-48}$

\subsection{Density functional theory (DFT) calculations}

The geometry optimization of the structures was carried using the Becke's three-parameter exchange functional and Lee-Yang-Parr correlation (B3LYP) method using GAMESS software. ${ }^{49,50}$ Theoretical calculations

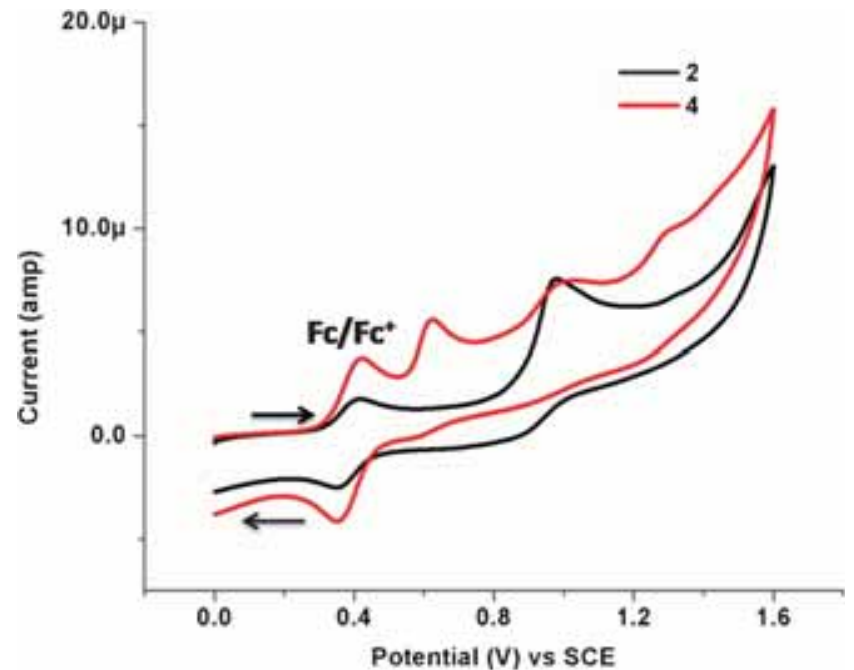

Figure 4. Cyclic voltammograms of compounds 2 and $\mathbf{4}$ in $\mathrm{CHCl}_{3}$ at a scan rate of $100 \mathrm{mV} / \mathrm{s}$ using tetrabutylammoniumhexafluorophosphate (TBAHFP) as supporting electrolyte.

based on density functional theory predict that the $\mathrm{S}_{0^{-}}$ $S_{1}$ transition of compounds 1-4 is responsible for these absorption and emission bands involving the HOMO and LUMO. $\mathrm{E}_{\mathrm{HOMO}}, \mathrm{E}_{\mathrm{LUMO}}$ and band gap calculated 
Table 2. Energy levels of 1-4 calculated using DFT and electrochemical methods.

\begin{tabular}{lccccc}
\hline Compound & ${ }^{\mathrm{a}} \mathrm{E}_{\text {Hомо }}(\mathrm{eV})$ & ${ }^{\mathrm{a}} \mathrm{E}_{\mathrm{LUMO}}(\mathrm{eV})$ & Band gap $(\mathrm{eV})$ & ${ }^{\mathrm{b}} \mathrm{E}_{\text {ox }}(\mathrm{V}$ vs SCE $)$ & ${ }^{\mathrm{c}} \mathrm{E}_{\text {Hомо }}(\mathrm{eV})$ \\
\hline 1 & -5.12 & -2.62 & 2.50 & 0.97 & -5.69 \\
2 & -5.21 & -2.83 & 2.38 & 0.99 & -5.71 \\
3 & -4.72 & -2.54 & 2.18 & 0.60 & -5.32 \\
4 & -4.80 & -2.73 & 2.07 & 0.62 & -5.34 \\
\hline
\end{tabular}

${ }^{\mathrm{a}}$ From DFT method; ${ }^{b}$ From cyclic voltammetry w.r.t. SCE; $\mathrm{E}_{\mathrm{ox}}$ for $\mathrm{Fc} / \mathrm{Fc}^{+}$w.r.t $\mathrm{SCE}=0.41 \mathrm{~V}$; ${ }^{c} \mathrm{E}_{\text {Hомо }}$ calculated from oxidation potentials (vs ferrocene) i.e., $\mathrm{E}_{\mathrm{HOMO}}=-$ (ox w.r.t. $\mathrm{Fc} / \mathrm{Fc}^{+}+$ $5.13 \mathrm{eV}) .^{51-54}$

form DFT calculations are summarized in Table 2. Values of $\mathrm{E}_{\text {номо }}$ determined by DFT calculation differs substantially from that of calculated using CV data. DFT calculations were performed in the gas phase conditions and effect of solvent is not considered in DFT, as is the case in CV. The solvent polarization effect could not be included in theoretical calculation. This could be one of the reasons of difference in the calculated and experimental $\mathrm{E}_{\text {Номо }}$ values. Trend obtained in calculated $\mathrm{E}_{\text {Номо }}$ for $\mathbf{1 - 4}$ is similar to experimental values. The electron density maps of these orbitals are shown in Figure 5. It is observed that the electronic $\pi$-system is localized on the BODIPY core and further extended to the pyrrole groups at the 3- and 5-positions. We believe this high delocalization of the $\pi$-electrons is responsible for the large optical red shifts observed for these dyes. Figure 5 also supports the extension of electron density in whole molecules with unequal distribution of electron density.

In compounds 1-4, pyrrole substituents at 3- or/and 5- positions showed strong red shift and quenching of fluorescence quantum yield with solvent polarity. Large bathochromic shifts of BODIPYs by the substitution of pyrrole groups at 3-and 5-positions of the BODIPY.
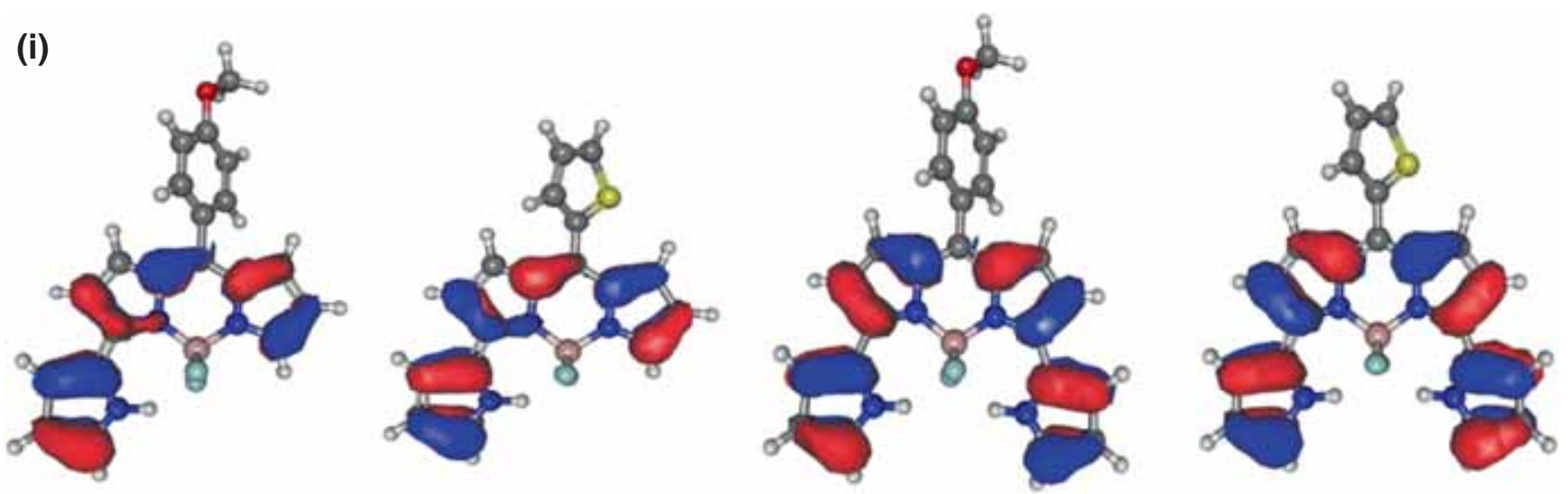

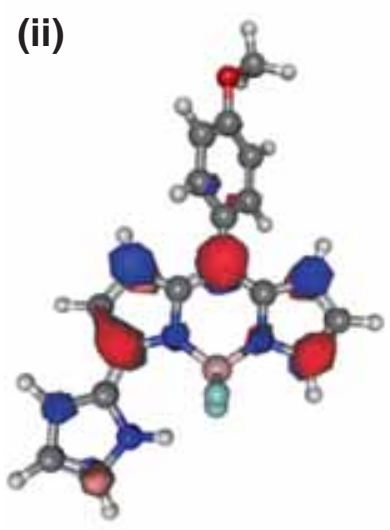

1

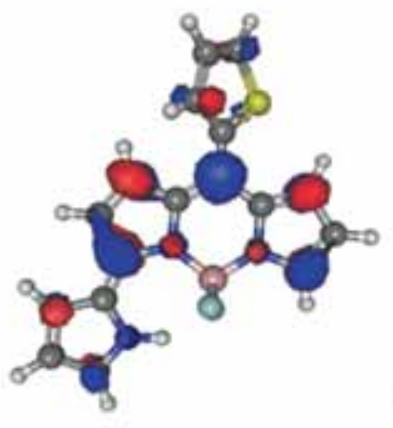

2

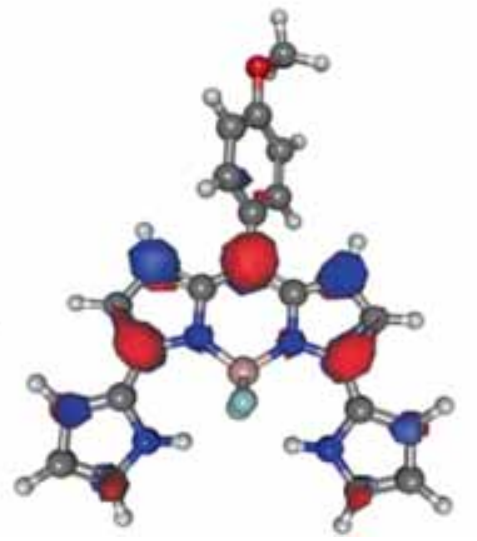

3

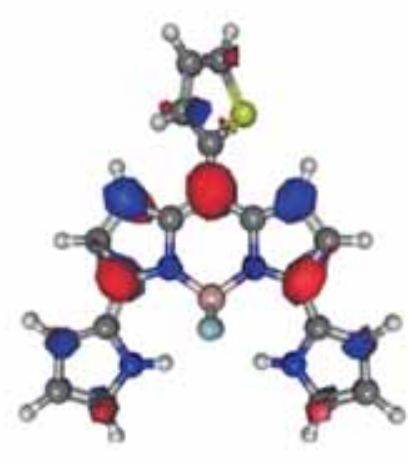

4

Figure 5. Optimized structures of compounds 1-4. (i) HOMO and (ii) LUMO generated using density functional calculations. 
Interaction between electron donating group (pyrrole) and $\pi$ electron clouds of BODIPY shifts electronic density from the donor substituent to the BODIPY core leading to the charge transfer state, which quenches the fluorescence emission efficiently, mainly in polar solvents. Fluorescence emission spectra of compounds 1-4 retained cyanine-like delocalization of BODIPY unit and show broadening of spectra in polar solvents.

\section{Conclusions}

To summarize, we have synthesized pyrrole substituted BODIPY derivatives using a simple one step nucleophilic substitution. Photophysical studies showed large bathochromic shifts in absorption and emission maxima as compared to the unsubstituted BODIPY. Solvatochromism was studied for 1-4 using the Lippert-Mataga equations which suggest strong polarization of monosubstituted BODIPYs as compared to di-substituted BODIPYs. Large bathochromic shift, their solvent dependence and DFT calculations suggest that pyrrole substituted BODIPY $\mathbf{1}$ and $\mathbf{2}$ are showing the properties of charge transfer states.

\section{Supplementary information (SI)}

Supplementary data of absorption and emission spectra, and $\mathrm{CV}$ data of BODIPY derivatives 1-4 in different solvents are available at www.ias.ac.in/chemsci.

\section{Acknowledgements}

KKJ, AN and Sanoj thank DST Inspire scholarships. Partial funding was provided by Department of Science and Technology, India (SR/FT/CS-87/2010). We also thank Tata Institute of Fundamental Research, Mumbai for providing the NMR, MALDI-TOF and TCSPC facilities.

\section{References}

1. Loudet A and Burgess K 2007 Chem. Rev. 1074891

2. Ziessel R, Ulrich G and Harriman A 2008 Angew. Chem. Int. Ed. 471184

3. Benniston A C, Harriman A, Whittle V L, Zelzer M, Harrington R W and Clegg W 2010 Photochem. Photobiol. Sci. 91009

4. Nepomnyashchii A B, Broering M, Ahrens J, Kruger R and Bard A J 2010 J. Phys. Chem. C 11414453

5. Thivierge C, Loudet A and Burgess K 2011 Macromolecules 444012

6. Gupta M, Mula S, Tyagi M, Ghanty T K, Murudkar S, Ray A K and Chattopadhyay S 2013 Chem. Eur. J. 1917766

7. Erten-Ela S, Yilmaz M D, Icli B, Dede Y, Icli S and Akkaya E U 2008 Org. Lett. 103299
8. Carlson J C T, Meimetis L G, Hilderbrand S A and Weissleder R 2013 Angew. Chem. Int. Ed. 526917

9. Ravikanth M, Agarwal N and Kumaresan D 2000 Chem. Lett. 29836

10. Kumaresan D, Agarwal N and Ravikanth M 2001 J. Chem. Soc., Perkin Trans. 11644

11. Kumaresan D, Agarwal N, Gupta I and Ravikanth M 2002 Tetrahedron 585347

12. Singh-Rachford T N, Haefele A, Ziessel R and Castellano F N 2008 J. Am. Chem. Soc. 13016164

13. Lakshmi V and Ravikanth M 2013 J. Org. Chem. 784993

14. Vincent M, Beabout E, Bennett R and Hewavitharanage P 2013 Tetrahedron Lett. 542050

15. Zhao C, Wang X, Cao J, Feng P, Zhang J, Zhang Y, Yang Y and Yang Z 2013 Dyes Pigm. 96328

16. Baruah M, Qin W, Flors C, Hofkens J, Vallée R A L, Beljonne D, Van der Auweraer M, De Borggraeve W M and Boens N 2006 J. Phys. Chem. A 1105998

17. Esnal I, Banuelos J, Lopez Arbeloa I, Costela A, GarcíaMoreno I, Garzon M, Agarrabeitia A R and Jose Ortiz M 2013 RSC Adv. 31547

18. Gautam P, Dhokale B, Mobin S M and Misra R 2012 RSC Adv. 212105

19. Jiao L, Pang W, Zhou J, Wei Y, Mu X, Bai G and Hao E 2011 J. Org. Chem. 769988

20. Jiao L, Yu C, Li J, Wang Z, Wu M and Hao E 2009 J. Org. Chem. 747525

21. Niu S, Ulrich G, Retailleau P and Ziessel R 2011 Tetrahedron Lett. $\mathbf{5 2} 4848$

22. Coskun A and Akkaya E U 2004 Tetrahedron Lett. 454947

23. Haefele A, Zedde C, Retailleau P, Ulrich G and Ziessel R 2010 Org. Lett. 121672

24. Ulrich G, Goze C, Goeb S, Retailleau P and Ziessel R 2006 New J. Chem. 30982

25. Lakshmi V and Ravikanth M 2012 J. Org. Chem. 768466

26. Wan C-W, Burghart A, Chen J, Bergström F, Johansson L B A, Wolford M F, Kim T G, Topp M R, Hochstrasser R M and Burgess K 2003 Chem. Eur. J. 94430

27. Bura T, Hablot D and Ziessel R 2011 Tetrahedron Lett. 522370

28. Buyukcakir O, Bozdemir O A, Kolemen S, Erbas S and Akkaya E U 2009 Org. Lett. 114644

29. Yakubovskyi V P, Shandura M P and Kovtun Y P 2009 Eur. J. Org. Chem. 3237

30. Lee J-S, Kang N-Y, Kim Y-K, Samanta A, Feng S, Kim H-K, Vendrell M, Park J H and Chang Y-T 2009 J. Am. Chem. Soc. 13110077

31. Liu J-Y, Yeung H-S, Xu W, Li X and Ng D K P 2008 Org. Lett. 105421

32. Lakhe D, Jairaj K K, Pradhan M, Ladiwala U and Agarwal N 2014 Tetrahedron Lett. 557124

33. Verbelen B, Boodts S, Hofkens J, Boens N and Dehaen W 2015 Angew. Chem. Int. Ed. 544612

34. Leen V, Miscoria D, Yin S, Filarowski A, Molisho Ngongo J, Van der Auweraer M, Boens N and Dehaen W 2011 J. Org. Chem. 768168

35. Rohand T, Baruah M, Qin W, Boens N and Dehaen W 2006 Chem. Commun. 266

36. Leen V, Gonzalvo V Z, Deborggraeve W M, Boens N and Dehaen W 2010 Chem. Commun. 464908 
37. Zhang M, Hao E, Zhou J, Yu C, Bai G, Wang F and Jiao L 2012 Org. Biomol. Chem. 102139

38. Jiang T, Zhang P, Yu C, Yin J, Jiao L, Dai E, Wang J, Wei Y, Mu X and Hao E 2014 Org. Lett. 141952

39. Laha J K, Dhanalekshmi S, Taniguchi M, Ambroise A and Lindsey J S 2003 Org. Process Res. Dev. 7799

40. Rao M R, Kumar K V P and Ravikanth M $2010 \mathrm{~J}$. Organomet. Chem. 695863

41. (a) Lopez Arbeloa T, Lopez Arbeloa F, Lopez Arbeloa I, Garcia-Moreno I, Costela A, Sastre R and Amat-Guerri F 1999 Chem. Phys. Lett. 299 315; (b) Kollmannsberger M, Rurack K, Resch-Genger U and Daub J 1998 J. Phys. Chem. A 10210211

42. (a) Banuelos Prieto J, Lopez Arbeloa F, Martınez V, Arbeloa Lopez T, Amat-Guerri F, Liras M and Lopez Arbeloa I 2004 Chem. Phys. Lett. 385 29; (b) Qin W, Baruaha M, Auweraer M V, De Schryver F C and Boens N 2005 J. Phys. Chem. A 1097371

43. Wagner R W and Lindsey J S 1996 Pure Appl. Chem. 681373

44. Kubin R F and Fletcher A N 1983 J. Lumin. 27455
45. Koti A S R, Bhattacharjee B, Haram N S, Das R, Periasamy N, Sonawane N D and Rangnekar D W 2000 J. Photochem. Photobiol. A 137115

46. Lee C, Yang W and Parr R G 1988 Phys. Rev. B 37785

47. Schmidt M W, Baldridge K K, Boatz J A, Elbert S T, Gordon M S, Jensen J H, Koseki S, Matsunga N, Nguyen K A, Su S J and et al. 1993 J. Comput. Chem. 141347

48. Kowada T, Maeda H and Kikichi K 2015 Chem. Soc. Rev. 444953

49. Debnath S, Singh S, Bedi A, Krishnamoorthy K and Zade S 2015 J. Phys. Chem. C 11915859

50. Singh S P and Gayathri T 2014 Eur. J. Org. Chem. 5689

51. Gritzner G and Kuta J 1984 Pure Appl. Chem. 56461

52. Mishra A, Nayak $\mathrm{P} \mathrm{K}$, Ray D, Patankar M P, Narasimhan K L and Periasamy N 2006 Tetrahedron Lett. 474715

53. Andrade B W D, Datta S, Forrest S R, Djurovich P, Polikarpov E and Thompson M E 2005 Org. Electron. 611

54. Nayak P K, Agarwal N, Ali F, Patankar M, Narasimhan K L and Periasamy N 2010 J. Chem. Sci. 122847 